\title{
DEMOCRACIA DE CIDADÃOS PROPRIETÁRIOS E O DEBATE IMPOSTO DE RENDA VERSUS REGRAS LEGAIS
}

\author{
PROPERTY-OWNING DEMOCRACY AND THE DEBATE INCOME TAX \\ VERSUS LEGAL RULES \\ Leandro Martins Zanitelli \\ Universidade Federal de Minas Gerais - UFMG - Belo Horizonte - Minas Gerais - Brasil
}

\begin{abstract}
Resumo: Rawls contrasta dois tipos de regime institucional, o "capitalismo de bem-estar" e a "democracia de cidadãos proprietários". O segundo se diferencia do primeiro por procurar atender a um certo ideal pré-distributivo, dispersando o capital (tanto material quanto humano) de maneira a que as relações de mercado sejam travadas em pé de mais aproximada igualdade. $O$ trabalho examina a relação entre a democracia de cidadãos proprietários e 0 debate imposto de renda versus regras legais como meio de distribuição. Uma primeira questão é se a preferência pela democracia de cidadãos proprietários em relação ao capitalismo de bem-estar tem alguma influência sobre o referido debate e, em particular, sobre a proclamada superioridade do imposto de renda como meio distributivo. A resposta, conforme o artigo, é não. Em segundo lugar, indaga-se se certas críticas à superioridade do imposto de renda, que chamam a atenção para as dificuldades da distribuição baseada em regras tributárias, são relevantes para a democracia de cidadãos proprietários. A resposta, nesse caso, é positiva. A fragilidade dos meios fiscais de distribuição convida a pensar em estratégias para a realização de uma democracia de cidadãos proprietários em que a dispersão do capital, ao invés apenas das políticas de tributação e transferência, seja realizada por meio de diferentes partes do sistema de direitos de propriedade.
\end{abstract}

Palavras-chave: Democracia de Cidadãos Proprietários; Pré-distribuição; Distribuição; Imposto de Renda; Direito Privado

Abstract: Rawls compares two types of institutional regime, "welfare state capitalism" and "property-owning democracy". The latter differs from the former by trying to satisfy a given predistributive ideal in which capital (both physical and human) is dispersed and market operations take place under conditions of proximate equality. The paper investigates the relation between propertyowning democracy and the income tax vs. legal rules debate. One question is whether a possible preference for property-owning democracy against welfare state capitalism matters for the proclaimed superiority of the income tax as a distributive tool. The answer, following the article, is negative. Another question is whether criticisms against the superiority of the income tax are relevant for property-owning democrats. The answer, in this case, is "yes". Some flaws of the income tax as a distributive means invite one to consider strategies to

Revista do Direito UNISC, ISSN: 1982-9957

Santa Cruz do Sul №. 48 | p. 145-166 | JAN-ABR 2016

https://online.unisc.br/seer/index.php/direito/index 
implement property-owning democracy and capital dispersion through several parts of the property rights system instead of only through tax-and-transfer policies.

Key-words: Property-Owning Democracy; Predistribution; Distribution; Income Tax; Private Law

\section{Introdução}

Há um debate em curso sobre o meio legal a empregar para fins distributivos. Supondo-se que o direito almeje resultados conformes a certos padrões de justiça distributiva, qual ou quais áreas da legislação devem ser voltadas à realização desse objetivo? Uma opinião bastante conhecida e popular entre economistas é que, ao menos se os padrões em questão disserem respeito à distribuição de renda e riqueza, o meio legal a ser empregado é o imposto de renda. Outras regras, em particular às relativas à propriedade e ao mercado, devem ser dirigidas a outros fins (nomeadamente, a eficiência), cabendo exclusivamente à legislação tributária corrigir os resultados do mercado.

O debate imposto de renda versus regras legais, ou legal rules (modo como se designam, nesse contexto, as regras de outros setores da legislação, incluindo-se aí as regras de direito privado sobre propriedade e contratos) tem corrido paralelamente a um outro, mais situado no âmbito da filosofia política, acerca do tipo de regime institucional mais consentâneo com a justiça. Ao discorrer sobre as instituições capazes de realizar os princípios da sua concepção de justiça (a "justiça como equidade"), Rawls compara diferentes tipos de regime institucional. Para ele, dois tipos de regime apresentam uma tendência a proporcionar resultados justos: o socialismo liberal e a democracia de cidadãos proprietários. ${ }^{1}$

Sobre esse tema, uma questão bastante comentada diz respeito à contraposição entre a democracia de cidadãos proprietários e o capitalismo de bem-estar. Embora as linhas gerais da teoria da justiça levem por vezes a pensar em Rawls como um defensor do welfare state, o fato é que ele não só trata o capitalismo de bem-estar e a democracia de cidadãos proprietários

\footnotetext{
${ }^{1}$ Entre os dois regimes defendidos, Rawls (2001, p. 139) afirma que cada sociedade deveria eleger o mais apropriado à sua tradição e circunstâncias.

Revista do Direito UNISC, ISSN: 1982-9957

Santa Cruz do Sul №. 48 | p. 145-166 | JAN-ABR 2016

https://online.unisc.br/seer/index.php/direito/index
} 
como regimes distintos, como afirma que só a segunda é compatível com os princípios da justiça como equidade.

Dizer que as instituições da democracia de cidadãos proprietários são propensas a conduzir a resultados justos em sentido rawlsiano é dizer que essas instituições estão alinhadas a certos princípios de justiça distributiva, tais como, por exemplo, o princípio da diferença. ${ }^{2}$ Uma pergunta a fazer seria, então, se interessa, e por que interessa, para o ideal da democracia de cidadãos proprietários o debate sobre 0 meio legal de distribuição mais apropriado. Outra é saber se a relevância do debate em questão é a mesma não importando o tipo de regime (contanto que se trate, evidentemente, de um regime com pretensões distributivas), de modo que a decisão sobre o meio a empregar - o imposto de renda, o direito privado ou outro - possa ser tomada independentemente do tipo de regime ou, ao menos, independentemente de qual dos dois regimes que Rawls contrasta, o capitalismo de bem-estar e a democracia de cidadãos proprietários, tenha-se em vista.

Acerca da relação entre o debate imposto de renda versus regras legais e os tipos de regime institucional - em particular, a democracia de cidadãos proprietários - o presente artigo se propõe a considerar duas hipóteses. A primeira é que, presumindo-se que estejamos de acordo com Rawls em preferir a democracia de cidadãos proprietários ao capitalismo de bem-estar, o debate sobre o meio legal de distribuição tenha de ser resolvido de uma maneira diferente da que seria caso o ponto-de-vista de Rawls fosse rechaçado. Essa primeira hipótese, conforme demonstrarei a seguir, é falsa. Caso correta, a opinião de que o imposto de renda é o meio mais adequado de distribuição é igualmente importante para o capitalismo de bem-estar e para a democracia de cidadãos proprietários.

A segunda hipótese é que certos contra-argumentos ao uso exclusivo do imposto de renda como meio de distribuição sejam importantes para a democracia de cidadãos proprietários porque informam acerca do modo como esse regime deve ser realizado. Essa hipótese, argumentarei, é correta. Como se verá a seguir, a democracia de cidadãos proprietários se distingue do

\footnotetext{
${ }^{2} \mathrm{O}$ princípio da diferença requer que a distribuição de certos bens primários, entre eles a riqueza e a renda, seja de molde a maximizar a vantagem dos cidadãos em pior situação (Rawls, 1999[1971], p. 68).
} 
capitalismo de bem-estar ao se propor a atender a um ideal pré-distributivo. Esse ideal, por sua vez, pode ser perseguido mediante duas estratégias, uma que consiste exclusivamente em transferências, e outra envolvendo transferências e um certo desenho do sistema de direitos de propriedade. Quanto a isso, o debate imposto de renda versus regras legais é importante porque certos argumentos contra o imposto de renda como meio exclusivo de distribuição sugerem que a segunda estratégia pode ser mais bem sucedida do que a primeira.

O trabalho é organizado do seguinte modo. Na primeira seção, apresenta-se a distinção entre os regimes do capitalismo de bem-estar e da democracia de cidadãos proprietários tal como feita por Rawls. Nela se afirma, em suma, que, enquanto o primeiro é um tipo de regime ocupado apenas com a redistribuição, a segunda se volta à realização de um certo ideal prédistributivo. A segunda seção apresenta os termos gerais do debate imposto de renda versus regras legais. Nela se rejeita a primeira das duas hipóteses acima referidas, a saber, a de que uma eventual preferência pela democracia de cidadãos proprietários tire força aos argumentos acerca da superioridade do imposto de renda como meio de distribuição. Essa seção distingue, ainda, as duas estratégias para satisfazer ao ideal pré-distributivo da democracia de cidadãos proprietários, a de transferências, exemplificada pela proposta de Williamson (2012), e a que combina transferências e um certo desenho dos direitos de propriedade. A terceira seção expõe, então, dois argumentos particularmente importantes contra o uso exclusivo do imposto de renda (e da tributação em geral) como meio de distribuição. A quarta e última seção conclui o trabalho e explica por que os argumentos da seção anterior convidam a levar a sério a ideia de uma democracia de cidadãos proprietários na qual a prédistribuição seja garantida pelo regime da propriedade como um todo, e não apenas por meio de transferências.

\section{Pré-distribuição e redistribuição}


"Mais pré-distribuição e menos redistribuição" é o lema de certos ideólogos e políticos de esquerda nos últimos anos. ${ }^{3}$ Para alguns (O’Neill; Williamson, 2012; Kerr, 2015), a diferença entre políticas pré-distributivas e redistributivas corresponde, em boa medida, à contraposição feita por Rawls entre dois tipos ideais de regime, a "democracia de cidadãos proprietários" (property-owning democracy) e o "capitalismo de bem-estar".

Para que se entenda em que sentido a democracia de cidadãos proprietários é um regime marcadamente pré-distributivo, é útil explicar, primeiro por que o capitalismo de bem-estar é redistributivo. Tal como definido aqui, o capitalismo de bem-estar é um regime de propriedade privada dos meios de produção e mercado aos quais se somam políticas de assistência aos incapazes de prover a própria subsistência, como crianças, idosos, vítimas de doenças incapacitantes e trabalhadores desempregados. Ele pode ser caracterizado, portanto, como um regime de tributação e transferência (taxand-transfer), que expropria parte da riqueza e da renda de alguns cidadãos para transferi-la, em dinheiro ou pela prestação de serviços, aos mais pobres.

$\mathrm{Na}$ democracia de cidadãos proprietários, em contrapartida, embora as políticas de taxação e transferência não sejam abandonadas, o objetivo principal é assegurar a dispersão do capital, tanto humano quanto físico. Almeja-se, com isso, que as relações de mercado sejam travadas em condições mais próximas às de igualdade, tanto em relação aos talentos ou aptidões (cujo desenvolvimento é perseguido mediante políticas educacionais), quanto em relação à riqueza e, em particular, à propriedade dos bens de produção, cuja concentração deve ser evitada.

Rawls descreve a diferença entre os dois regimes na passagem a seguir transcrita (2001, p. 139):

Uma diferença principal é a seguinte: as instituições de fundo da
democracia de cidadãos proprietários trabalham para dispersar a
riqueza e o capital, evitando, assim, que uma pequena parte da
sociedade controle a economia e, indiretamente, a vida política
também. Em contraste, o capitalismo de bem-estar permite a uma
pequena classe o quase monopólio dos meios de produção. A

${ }^{3}$ Notadamente no Reino Unido, onde o termo foi usado por Ed Miliband para designar a plataforma do partido trabalhista. Para referências sobre a popularidade do termo em publicações científicas e textos de jornais nos últimos anos, v. Kerr (2015).

${ }^{4}$ As ideias de Rawls sobre as características de uma democracia de cidadãos proprietários têm inspiração em um trabalho do economista britânico James Meade (Meade, 2012[1964]). Para uma história do conceito de democracia de cidadãos proprietários, v. Jackson (2012).

Revista do Direito UNISC, ISSN: 1982-9957

Santa Cruz do Sul №. 48 | p. 145-166 | JAN-ABR 2016

https://online.unisc.br/seer/index.php/direito/index 
democracia de cidadãos proprietários evita isso não mediante a redistribuição de renda em favor dos que têm menos ao fim de cada período, por assim dizer, mas, sobretudo, assegurando a dispersão da propriedade sobre bens produtivos e o capital humano (isto é, a educação e as habilidades adquiridas) no início de cada período, tudo isso contra um pano-de-fundo de equitativa igualdade de oportunidades. A intenção não é apenas assistir aos que saem perdendo devido ao azar ou acidente (embora isso tenha de ser feito) mas antes fazer com que todos os cidadãos estejam em posição de gerir seus negócios em um adequado pé de igualdade econômica e social. $^{5}$

A democracia de cidadãos proprietários é pré-distributiva, portanto, no sentido de que atenta para as circunstâncias nas quais as decisões quanto à produção e ao mercado são tomadas, e não apenas para as consequências dessas decisões. A ideia é que a liberdade para o comércio e a produção seja exercida por agentes em pé de aproximada igualdade, seja quanto às aptidões (ou capital humano), seja quanto à propriedade dos meios de produção. Espera-se que, graças a políticas que promovam a pré-distribuição no sentido referido, a importância de políticas redistributivas dirigidas a contrapesar os resultados do mercado seja reduzida, muito embora essas políticas conservem um papel residual.

Não é o caso de examinar aqui os argumentos acerca da maior propensão da democracia de cidadãos proprietários (quando comparada ao capitalismo de bem-estar) para satisfazer aos princípios da concepção rawlsiana de justiça, a justiça como equidade. É suficiente mencionar, a título de ilustração, que esses argumentos se referem ao valor equitativo das liberdades políticas (que a concentração da riqueza permitida pelo capitalismo de bem-estar põe em risco), à equitativa igualdade de oportunidades (a que a democracia de cidadãos proprietários procura satisfazer com suas medidas para a dispersão do capital humano) e ao princípio da diferença (à luz do qual a democracia de cidadãos proprietários se mostra preferível ao promover a

\footnotetext{
${ }^{5}$ No original: "One major difference is this: the background institutions of property-owning democracy work to disperse the ownership of wealth and capital, and thus to prevent a small part of society from controlling the economy, and indirectly, political life as well. By contrast, welfare-state capitalism permits a small class to have a near monopoly of the means of production. Property-owning democracy avoids this, not by redistribution of income to those with less at the end of each period, so to speak, but rather by ensuring the widespread ownership of productive assets and human capital (that is, education and training skills) at the beginning of each period, all this against a background of fair equality of opportunity. The intent is not simply to assist those who lose out through accident or misfortune (although that must be done), but rather to put all citizens in a position to manage their own affairs on a footing of a suitable degree of social and economic equality."
}

Revista do Direito UNISC, ISSN: 1982-9957

Santa Cruz do Sul №. 48 | p. 145-166 | JAN-ABR 2016

https://online.unisc.br/seer/index.php/direito/index 
independência e, com ela, o autorrespeito dos cidadãos) (Rawls, 2001, p. 137138; para uma crítica, v. O’Neill, 2012).

\section{Democracia de cidadãos proprietários, capitalismo de bem-estar e a alegada superioridade do imposto de renda}

Esclarecidos os termos da contraposição entre democracia de cidadãos proprietários e capitalismo de bem-estar e o sentido no qual, de acordo com a descrição de Rawls, a primeira tem como objetivo eminente a pré-distribuição, enquanto o segundo é exclusivamente redistributivo, esta seção examina se, e em que medida, interessa para essa contraposição o debate sobre regras legais versus imposto de renda como meios distributivos. Começo, assim, com uma caracterização geral desse debate.

É comum comparar-se a eficiência do imposto de renda e das regras legais (legal rules) como meios distributivos. "Regras legais" é uma denominação um tanto frouxa que serve aqui para designar quaisquer disposições legais que não as do imposto de renda (ou, alternativamente, quaisquer disposições legais não tributárias) de cujo uso para fins distributivos se cogite. Entre essas "outras" disposições legais estão disposições pertencentes a áreas tradicionais do direito privado, como as da propriedade, dos contratos e da responsabilidade civil. Embora não se limitem a isto, argumentos sobre a superioridade (em termos de eficiência) do imposto de renda como instrumento de distribuição são frequentemente entendidos como argumentos que se opõem ao uso distributivo do direito privado (e.g., Lewinsohn-Zamir, 2006; Keren-Paz, 2007).

Como "uso distributivo do direito privado" deve se entender, por sua vez, o desenho de regras de direito privado (tanto no âmbito legislativo como em sua aplicação pelos juízes) para atender a princípios de justiça distributiva (e.g., o princípio da diferença de Rawls). É importante notar, porém, que o debate imposto de renda versus regras legais em geral não tem em vista o uso distributivo do direito privado indiscriminadamente, mas apenas se contrário à eficiência. Para os partidários do imposto de renda como solução distributiva, não há mal nenhum se (por uma feliz coincidência) uma regra de direito privado 
for ao mesmo tempo eficiente e distributivamente desejável. O mal está, sim, em que, para perseguir objetivos distributivos, as regras de direito privado (assim como outras que não as tributárias) sejam delineadas de maneira não eficiente, já que os referidos objetivos poderiam ser realizados com menor desperdício de recursos (isto é, mais eficientemente) por meio da tributação.

Pois bem, suponhamos que críticos do uso distributivo do direito privado tenham razão em afirmar que o imposto de renda é o meio a empregar para a realização da justiça distributiva, e que, portanto, as regras de direito privado devam ser "liberadas" para a obtenção de outros fins, entre eles, nomeadamente, a eficiência. O que tal afirmação implica para os regimes do capitalismo de bem-estar e da democracia de cidadãos proprietários e, em particular, para o interesse pela pré-distribuição verificado nessa última?

$O$ debate imposto de renda versus regras legais parece correr paralelamente ao debate sobre os tipos de regime que Rawls distingue. De um lado, para o capitalismo de bem-estar, o que importa é que parte das vantagens que o mercado proporciona a alguns cidadãos seja expropriada a fim de custear as políticas de assistência aos desfavorecidos. "Taxação e transferência", ou tax-and-transfer, não quer dizer, necessariamente, redistribuição baseada no imposto de renda. Em tese, os resultados do mercado poderiam ser corrigidos por uma regra de responsabilidade civil que mandasse pagar indenizações superiores ao dano em casos nos quais o autor da ação seja pobre e o réu rico, ou por uma regra de direito administrativo que faça o valor das multas de trânsito variar de acordo com a renda do infrator. Se o imposto de renda for, de fato, o meio mais eficiente para que essas correções sejam feitas, tanto melhor então que, ao invés da responsabilidade civil, seja a tributação o meio usado para angariar os fundos necessários às políticas de assistência. Uma conclusão em sentido contrário, contudo, nada mudaria substancialmente quanto à caracterização do capitalismo de bem-estar.

Consideremos agora o caso da democracia de cidadãos proprietários. Viu-se que, diferentemente do capitalismo de bem-estar, a democracia de cidadãos proprietários não se contenta em corrigir os resultados do mercado (embora ocasionalmente o faça), pois trata também de prover condições para que esses resultados estejam o menos distante possível do ideal. Que 
importância teria, então, para a democracia de cidadãos proprietários a alegada superioridade do imposto de renda como meio distributivo (ou seu eventual desmentido)?

A resposta é, em princípio, nenhuma, ou, ao menos, nenhuma se admitirmos que o imposto de renda (ou outro meio, ou ambos) seja capaz de arrecadar recursos suficientes para financiar políticas que assegurem a realização do objetivo pré-distributivo característico da democracia de cidadãos proprietários. Suponha, para exemplificar, que aceitemos a versão de democracia de cidadãos proprietários defendida por Williamson (2012), na qual cada cidadão recebe, ao longo da vida, um total de $\$ 50.000$, parte deles para uso livre e parte para fins previamente designados, como aquisição de moradia e investimentos em produção. Uma proposta como essa poderia (e é, de fato, o que Williamson imagina) ser financiada pela tributação da riqueza e da renda dos mais ricos. Se esse for, de fato, um meio capaz de obter os recursos necessários para o programa em questão, nada haverá na ideia de democracia de cidadãos proprietários (ao menos em uma versão tal como a aqui considerada) que se oponha a "liberar" o direito privado de qualquer finalidade distributiva.

A preferência pela democracia de cidadãos proprietários em relação ao capitalismo de bem-estar não tem, portanto, uma necessária implicação para o debate imposto de renda versus regras legais. A diferença entre os dois tipos de regime reside no que aspiram fazer com os recursos que arrecadam: no caso do capitalismo de bem-estar, trata-se de prover as necessidades básicas da parcela mais desfavorecida da população, enquanto que, no da democracia de cidadãos proprietários, de prover essas necessidades e instituir condições que reduzam a desigualdade das relações de mercado, reduzindo-se também, em consequência, a parte da população cujas necessidades básicas 0 mercado não é capaz de atender.

Dito isso, considere agora como o debate imposto de renda versus regras legais pode, sim, ser importante para o tema em análise se a versão de democracia de cidadãos proprietários que almejarmos for um pouco diferente da proposta por Williamson (2012). Há, de fato, várias maneiras de realizar o ideal da pré-distribuição. Em algumas delas, a pré-distribuição é obtida 
mediante transferências de recursos em favor de alguns cidadãos a fim de muni-los de capital tanto direta quanto indiretamente (dada a possibilidade de que os recursos sejam investidos na aquisição de capital humano). Em outras, diferentemente, a pré-distribuição pode envolver um certo desenho do sistema de direitos de propriedade, de tal maneira a que esse sistema ganhe características que, se não assegurem, ao menos contribuam para prevenir o acúmulo de riqueza e as relações de dominação que daí advêm. ${ }^{6}$

Tendo em vista que essa distinção entre transferências de recursos e desenho do sistema de direitos de propriedade (como soluções institucionais para a realização do ideal pré-distributivo) é crucial para o meu argumento aqui, será preciso que nos detenhamos nela antes de reavaliar a importância do debate imposto de renda versus regras legais. A distinção em questão depende de uma particular maneira de se conceberem os direitos de propriedade e seu respectivo sistema. Pensemos, então, em direitos de propriedade como direitos de uso e exclusão sobre certos recursos, de modo que a existência de direitos de propriedade se contraponha a um sistema de acesso aberto (open access), em que ninguém tenha direito a impedir o uso dos recursos por quem quer que seja. Um sistema de direitos de propriedade, por sua vez, é um conjunto de regras definindo quais recursos são objeto de direitos de propriedade, a extensão desses direitos (isto é, o que é permitido fazer com cada recurso), as medidas para assegurar o uso exclusivo e os modos de aquisição, transferência e perda.

Assim entendido, um sistema de direitos de propriedade é também um sistema com regras sobre transferências, incluindo-se, aí, eventuais transferências destinadas à realização de certo ideal pré-distributivo. No seu todo, entretanto, o regime jurídico da propriedade é constituído por muito mais do que regras sobre transferências. Além disso, mesmo em relação a essas últimas, é possível distinguir entre as que consistem em transferências comandadas legalmente a fim de alcançar um objetivo pré-distributivo e

\footnotetext{
${ }^{6}$ Um exemplo de democracia de cidadãos proprietários na qual a situação pré-distributiva desejada não é alcançada apenas mediante transferência é o que inclua, na caracterização do regime em questão, algum princípio quanto à participação dos trabalhadores na gestão das empresas. V., sobre isso, Hsieh (2012). A ideia de uma pré-distribuição não dependente de transferências também aparece em trabalhos que não têm em vista a teoria da justiça de Rawls e a democracia de cidadãos proprietários, como os de De Geest (2014) e Colander (2014).

Revista do Direito UNISC, ISSN: 1982-9957

Santa Cruz do Sul №. 48 | p. 145-166 | JAN-ABR 2016

https://online.unisc.br/seer/index.php/direito/index
} 
transferências que tenham lugar voluntariamente, por meio de contratos ou de atos de disposição causa mortis. Em outras palavras, nem todas as transferências a que um sistema de direitos de propriedade se refere são transferências forçadas.

Uma democracia de cidadãos proprietários como a idealizada por Williamson (2012) tem lugar por meio de regras sobre transferência forçada, sem fazer, portanto, maiores requerimentos quanto às demais partes do sistema de direitos de propriedade. Como a democracia de cidadãos proprietários é geralmente caracterizada como um regime de propriedade privada dos meios de produção e mercado, presume-se, no entanto, que deva haver algum sistema assim. Como o que assegura a pré-distribuição, contudo, são exclusivamente as transferências forçadas, não há maior preocupação com as demais regras de propriedade.

Suponha agora, em contrapartida, que a estratégia para a realização do ideal pré-distributivo não envolva apenas transferências. Poder-se-ia constatar, por exemplo, que certas regras quanto à aquisição e extensão de direitos de propriedade sobre invenções (patentes) são, sob o ponto de vista prédistributivo, preferíveis a outras, e caracterizar então a democracia de cidadãos proprietários como regime do qual fazem parte essas regras.

Se a versão da democracia de cidadãos proprietários que se tem em vista depender apenas de transferências, então ela pode, de fato, uma vez provado que o melhor instrumento para a realização das transferências em questão seja o imposto de renda, manter-se alheia ao direito privado. Outro será o caso, no entanto, se tivermos em vista uma solução institucional que, a fim de garantir condições pré-distributivas, caracterize-se por um certo desenho de outras partes do sistema de direitos de propriedade (não se limitando, pois, a regras de transferências). É muito provável que o ideal de democracia de cidadãos proprietários inclua então certas disposições de direito privado, área do direito à qual pertence parte significativa das regras sobre a propriedade.

Uma das razões para considerar importante o debate imposto de renda versus regras legais consiste, pois, no seguinte. Como regime que, diferentemente do capitalismo de bem-estar, procura certo resultado prédistributivo, a democracia de cidadãos proprietários pode alcançar esse 
desiderato mediante transferências apenas ou todo o sistema de direitos de propriedade (ou, ao menos, diversas partes dele). Por um lado, então, a alegada superioridade do imposto de renda como instrumento de custeio de transferências é menos relevante para a democracia de cidadãos proprietários, regime para o qual as transferências podem não ser o único meio de distribuição. Por outro, pode-se dizer que o fato de haver dificuldades para que transferências tenham lugar por meio da tributação leva a pensar não apenas em soluções legais alternativas para essas transferências mesmas, mas também no uso de uma estratégia que envolva um redesenho mais amplo das regras de propriedade.

Na próxima seção, apresentarei argumentos que dão força a essa última sugestão. Contra a opinião tradicional acerca da superioridade do imposto de renda como instrumento de distribuição (e avessa, consequentemente, a um uso do direito privado contrário à eficiência), parte da literatura vem chamando a atenção para dificuldades enfrentadas pela distribuição dependente da tributação. Esses argumentos, que poderiam se limitar a recomendar o uso de outros meios legais para a realização de transferências, quando vistos à luz do ideal da democracia de cidadãos proprietários, levam a pensar em políticas pré-distributivas que também envolvam outras partes do sistema de direitos de propriedade.

\section{4. $O$ argumento da dupla distorção e seus limites}

Há vários argumentos contra o uso distributivo do direito privado. Primeiro, com respeito a regras contratuais que pretendam beneficiar algum dos contratantes (por exemplo, o locatário, em contratos de locação de imóvel), afirma-se que é possível contrapesar os efeitos dessas regras mediante uma alteração das condições contratuais (argumento da ineficácia). Por exemplo, em resposta a uma regra que pretenda beneficiar locatários com um limite para a multa a pagar em caso de atraso, proprietários podem aumentar aluguéis, compensando-se antecipadamente por eventuais atrasos. Segundo, a distribuição feita com regras de direito privado é também acusada de imprecisão, porque as classes de pessoas às quais as regras de direito privado 
se aplicam não correspondem precisamente àquelas a favor e contra quem a distribuição é desejada (argumento da imprecisão). Admitindo-se, por exemplo, que a distribuição desejada envolva ricos e pobres, regras em favor de consumidores ou de pedestres são imprecisas, já que nem todos os consumidores e pedestres são pobres e nem todos os fornecedores e motoristas são ricos. Terceiro, a distribuição baseada no direito privado tem ainda o inconveniente de ser aleatória (argumento da aleatoriedade). Por exemplo, uma regra distributiva em favor de pedestres beneficiará apenas os pedestres que forem vítimas de acidente de trânsito e fará a distribuição apenas à custa dos motoristas que causarem acidentes. ${ }^{7}$

O libelo contra o uso distributivo do direito privado é completado pelo argumento da "dupla distorção" (double distortion), ${ }^{8}$ de Kaplow e Shavell (2000; 1994). De acordo com esse argumento, o direito privado é não apenas um meio potencialmente ineficaz, impreciso e aleatório de se fazer distribuição: ele (assim como outras regras legais não tributárias) é também, quando comparado ao imposto de renda, ineficiente. Para entender por quê, considere, primeiro, que a distribuição baseada no direito privado tem um efeito distorcivo que é comum ao imposto de renda, o da substituição do trabalho pelo lazer. Quando a distribuição é feita à custa dos que auferem mais renda, cria-se um incentivo para que atividades relacionadas à renda (como o trabalho) sejam substituídas por outras que não o são (como o lazer). ${ }^{9}$ Essa substituição do trabalho pelo lazer (a "primeira distorção") é independente do meio legal (a tributação ou outro) pelo qual a distribuição tem lugar. Em outras palavras, para o desincentivo ao trabalho, é indiferente que a renda seja tributada ou que os cidadãos com maior renda sejam condenados a pagar indenizações maiores por ilícitos civis, contanto que a proporção da renda taxada nos dois casos seja a mesma.

\footnotetext{
${ }^{7}$ Para uma exposição mais detida sobre esses argumentos e seus limites, v. Logue e Avraham (2003, p. 177-188).

${ }^{8}$ A denominação, hoje popularizada, é de um dos críticos do argumento, Sanchirico (2000, p. 799).

${ }^{9}$ A distorção a que o texto se refere também pode consistir na substituição de um trabalho de maior por outro de menor remuneração. Admitindo-se que a renda seja uma medida do valor social do trabalho, a substituição de uma atividade de renda maior por outra de renda menor (mas, provavelmente, menos penosa para o trabalhador) também é, ceteris paribus, ineficiente. De todo o modo, o importante para o argumento da dupla distorção é que, qualquer que seja o efeito distorcivo da tributação da renda, esse é um efeito reproduzido por regras distributivas de direito privado pelas quais a renda seja taxada em igual quantidade.
}

Revista do Direito UNISC, ISSN: 1982-9957

Santa Cruz do Sul №. 48 | p. 145-166 | JAN-ABR 2016

https://online.unisc.br/seer/index.php/direito/index 
Mas se o imposto de renda e outras regras legais de taxação da renda têm o mesmo efeito distorcivo quanto ao trabalho, somente essas últimas causam ainda uma outra distorção (a "segunda"), a que se relaciona à atividade à qual a regra se aplica. No caso do imposto de renda, o que determina a taxação é a renda, independentemente da atividade pela qual ela é auferida. $^{10}$ Já no caso de outras regras, como as de direito privado, não. Regras distributivas de responsabilidade civil, por exemplo, não se aplicam a todo e qualquer cidadão cuja renda tenha alcançado o patamar taxável, mas apenas aos cidadãos com renda a partir desse patamar que exerçam (e à medida que exerçam) atividades causadoras de dano. O segundo efeito distorcivo consiste, pois, em incentivar a substituição das atividades sujeitas às regras distributivas por outras socialmente menos desejáveis. No caso de uma regra distributiva de responsabilidade civil, a referida distorção tem lugar quando atividades que, apesar do potencial danoso, são socialmente valiosas, são substituídas por outras menos valiosas.

De acordo com o argumento da dupla distorção, portanto, toda e qualquer distribuição que se cogite fazer por meio do direito privado poderia ser replicada com vantagem pelo imposto de renda, cuja ineficiência se limita ao efeito distorcivo quanto ao trabalho. Regras de direito privado não devem, pois, almejar qualquer resultado distributivo, ou ao menos não quando esse resultado não puder ser perseguido sem causar alguma distorção adicional (em outras palavras, quando o objetivo distributivo estiver em desacordo com a eficiência).

O argumento da dupla distorção se sujeita, contudo, a ressalvas importantes. Ter em vista essas ressalvas leva a repensar o papel distributivo do direito privado, apesar das dificuldades salientadas pelos argumentos da ineficácia, da imprecisão e da aleatoriedade. Leva, também, a cogitar versões de uma democracia de cidadãos proprietários em que a pré-distribuição desejada dependa não exclusivamente de transferências.

\footnotetext{
${ }^{10}$ Essa é, ao menos, a versão "pura" do imposto de renda que o argumento da dupla distorção tem em vista. À medida que a legislação do imposto de renda faça diferenciações baseadas na atividade pela qual a renda é obtida, essa legislação terá um segundo efeito distorcivo similar ao descrito a seguir no texto. A diferença, pode-se dizer, é que as regras do imposto de renda podem vir em uma versão pura (ou neutra quanto à atividade), enquanto que as regras distributivas de direito privado necessariamente se relacionam ao exercício de determinadas atividades além da auferição da renda em si.
}

Revista do Direito UNISC, ISSN: 1982-9957

Santa Cruz do Sul №. 48 | p. 145-166 | JAN-ABR 2016

https://online.unisc.br/seer/index.php/direito/index 
A literatura crítica ao argumento da dupla distorção é abundante. ${ }^{11}$ Das várias respostas suscitadas, atenho-me a seguir a duas delas, cujo alcance as torna, ao meu ver, especialmente relevantes. Essas respostas chamam a atenção para a importância de duas premissas "ocultas" do argumento. Uma vez provada a fragilidade das premissas em questão, o argumento da dupla distorção perde boa parte da sua força.

Uma das referidas premissas é objeto de um artigo recente de Fennell e McAdams (2015). Segundo esses autores, o argumento da dupla distorção somente leva à conclusão de que o direito privado (bem como outras regras legais que não as do imposto de renda) deve se manter alheio a fins distributivos caso não haja entraves políticos a que a distribuição ambicionada se obtenha por meio da legislação fiscal, ou então caso esses entraves, se existirem, forem ao menos tão consideráveis quanto os entraves ao uso distributivo do direito privado (o que Fennell e McAdams chamam de "hipótese da invariância"). Suponha que estejamos preocupados com a justiça distributiva, e que os óbices políticos a regras de direito privado distributivamente desejáveis sejam menores do que os enfrentados pelo imposto de renda. Em tais circunstâncias, podemos concordar em sacrificar a eficiência a fim de realizar a justiça pelo meio mais disponível, politicamente falando.

Fennell e McAdams não são os primeiros a chamar a atenção para o fato de que o argumento da dupla distorção só condena o uso distributivo do direito privado sob a presunção de que não haja entraves políticos comparativamente maiores a que o estado de distribuição desejado seja alcançado pelo imposto de renda (v., e.g., Keren-Paz, 2007, p. 53-54). A particularidade do trabalho de Fennell e McAdams está em apresentar argumentos em favor da conclusão de que essa presunção é, frequentemente, falsa. Segundo eles, medidas distributivas são tão mais fáceis de instituir quanto mais aceitáveis se mostrem e, contrariamente ao que se pode imaginar, a aceitabilidade de uma medida não depende apenas da magnitude dos seus

\footnotetext{
${ }^{11}$ Para trabalhos críticos ao argumento de Kaplow e Shavell, v., além dos citados a seguir no texto, De Geest (2014), Keren-Paz (2007, p. 42-54), Lewinsohn-Zamir (2006), Avraham, Fortus e Logue (2004), Logue e Avraham (2003), Sanchirico (2000; 2001) e Jolls (1998).

Revista do Direito UNISC, ISSN: 1982-9957

Santa Cruz do Sul №. 48 | p. 145-166 | JAN-ABR 2016

https://online.unisc.br/seer/index.php/direito/index
} 
benefícios e custos, mas também do modo como ela é percebida e das preferências do público quanto à justiça (fairness). ${ }^{12}$

Consideremos separadamente os dois pontos. Quanto ao primeiro, Fennell e McAdams afirmam que a reação negativa a uma proposta com fins distributivos pode variar de acordo com a maneira como a proposta em questão é percebida. A ideia é que duas medidas podem ser cognitivamente "enquadradas" (framed) de modo distinto, apesar de seus resultados serem similares (Fennell; McAdams, 2015, p. 30-34). A tributação costuma ser encarada como medida de expropriação, pela qual se tira algo de certos cidadãos para dar a outros (o que o termo "redistribuição" também sugere). Há, consequentemente, uma tendência a que ela suscite mais resistência do que medidas cujos efeitos não sejam cognitivamente enquadrados como perdas, tal como mudanças nas regras de aquisição e transferência voluntária dos direitos de propriedade.

Segundo, as preferências do público quanto à justiça também podem influir sobre as chances de sucesso de uma regra legal distributiva, considerando-se aí tanto as chances de promulgação da regra como de que ela seja obedecida (Fennell; McAdams, 2015, p. 34-42). Por exemplo, embora a provisão de benefícios em espécie (por exemplo, em saúde e moradia) seja igualmente custosa e ineficiente quando comparada à provisão do equivalente em dinheiro, benefícios em espécie podem enfrentar menos oposição. Aos olhos de alguns cidadãos, é justo que os mais pobres tenham certas necessidades atendidas, mas não que sejam livres para dispor dos recursos de políticas assistenciais do modo que lhes aprouver. A questão não é, evidentemente, avaliar se os cidadãos que pensam assim estão corretos. Trata-se, ao invés disso, tão-somente de constatar que, dadas as opiniões do público acerca do que é justo, medidas distributivas bastante similares no que respeita a benefícios e custos podem enfrentar obstáculos políticos de diferente magnitude. Fennell e McAdams (2015, p. 36) também aludem, a esse respeito,

\footnotetext{
${ }^{12}$ Parte dos argumentos de Fennell e McAdams é destinada a contestar uma outra afirmação de Kaplow e Shavell, a saber, a de que eventuais manobras distributivas de órgãos não legislativos (por exemplo, dos juízes, na interpretação das leis) provocariam a pronta resposta do órgão legislativo, o qual trataria, então, de se contrapor aos efeitos das referidas manobras para restaurar o estado distributivo da sua preferência. Fennell e McAdams (2015, p. 23-30) contestam a presunção de hipersensibilidade e capacidade ilimitada de reação dos legisladores contida nessa afirmação.
}

Revista do Direito UNISC, ISSN: 1982-9957

Santa Cruz do Sul №. 48 | p. 145-166 | JAN-ABR 2016

https://online.unisc.br/seer/index.php/direito/index 
à proverbial impopularidade da tributação, relacionada, possivelmente, à ideia de que os resultados do mercado são merecidos e, consequentemente, justos. Em contrapartida, "alterações institucionais das 'regras do jogo' que engendram os resultados do mercado podem ter efeitos distributivos mais poderosos e persistentes caso sejam entendidas como parte de um processo essencialmente justo de produção de resultados." ${ }^{13}$

Outra premissa implícita no argumento da dupla distorção é que os agentes nada podem fazer para se furtarem licitamente à aplicação de uma regra distributiva, ou que, se é possível escapar à aplicação da regra, isso é igualmente fácil para o imposto de renda e as regras legais. Sem essa premissa, o argumento da dupla distorção também perde força. Mesmo admitindo que o imposto de renda seja superior em termos de eficiência, se os agentes conseguirem se esquivar à sua aplicação com particular facilidade, outros meios de distribuição, ainda que comparativamente ineficientes, podem ser preferíveis.

A importância da "fuga à jurisdição", isto é, de artifícios lícitos para escapar à aplicação de um sistema legal é tema de um artigo recente de Dagan (2014) sobre o debate imposto de renda versus regras legais. ${ }^{14} \mathrm{De}$ acordo com essa autora, apesar da ineficiência, regras legais podem ser preferíveis como meio de distribuição caso o incentivo para escapar à sua aplicação seja menor. De um modo geral, o atrativo para fugir de uma regra distributiva é uma função de custos e benefícios, a saber: custos com as medidas a tomar para não se sujeitar à regra em questão e benefícios decorrentes da aplicação de uma regra alternativa. Uma conclusão importante a tirar, pois, é que o incentivo para fugir a uma jurisdição é tanto menor quanto menor diversificação houver em diferentes países ou jurisdições em relação a certos temas. De pouco servirá fazer uso de artifícios para se submeter à ordem legal do país $A$ ao invés da do país $B$ se as legislações dos dois países forem muito similares.

Algo importante salientado por Dagan (2014) é que os custos e benefícios da fuga à jurisdição podem variar para diferentes regras ou áreas de

\footnotetext{
${ }^{13}$ No original: "[i]nstitutional changes to the "rules of the game" that generate market results may have a more powerful and stickier effect on distributive results if they are understood to be part of an essentially fair process for producing outcomes."

${ }^{14} \mathrm{O}$ mesmo ponto foi levantado antes por Galle (2010), embora menos detalhadamente.

Revista do Direito UNISC, ISSN: 1982-9957

Santa Cruz do Sul №. 48 | p. 145-166 | JAN-ABR 2016

https://online.unisc.br/seer/index.php/direito/index
} 
um mesmo sistema legal. A legislação pode ser de molde a tornar menos custoso escapar a uma regra de tributação (o que pode depender, por exemplo, de mera mudança do domicílio fiscal) do que a uma regra de responsabilidade civil (para fugir da qual geralmente é preciso abrir mão do exercício de toda e qualquer atividade potencialmente danosa em certa localidade). O grau de harmonização entre os países quanto a diferentes setores da legislação também pode variar e, com ele, a vantagem de transitar de uma ordem legal para outra.

Uma possível desvantagem, portanto, do imposto de renda e da legislação tributária em geral como meios de distribuição é a de serem mais propensos à fuga do que outras regras. ${ }^{15}$ Apesar da ineficiência, pois, o uso de regras legais (entre elas as de direito privado) para fins distributivos pode ser justificado. ${ }^{16}$

\section{Conclusão}

Argumentos como os apresentados na seção anterior contestam a ideia de que o debate imposto de renda versus regras legais como meio de distribuição seja invariavelmente resolvido em favor do primeiro. Mesmo que o argumento da dupla distorção esteja certo em acusar a ineficiência de regras legais como as do direito privado, razões de justiça podem, em certas circunstâncias, demandar o uso de regras assim para fins distributivos. Que lições podem ser tiradas daí para a democracia de cidadãos proprietários?

Uma primeira conclusão é que se quisermos atender ao ideal prédistributivo da democracia de cidadãos proprietários mediante transferências, talvez seja o caso de cogitar de outros meios para angariar os recursos necessários a essas transferências que não o fiscal. A ideia, por exemplo, de

\footnotetext{
${ }^{15} \mathrm{~A}$ conclusão do artigo de Dagan não é a de que, dada a possibilidade de fuga à jurisdição, a legislação tributária seja um meio de distribuição em geral mais inócuo do que outros. O que ele afirma, mais cautelosamente, é que, em virtude do fato de os incentivos para escapar à aplicação de regras poderem variar, não se pode a priori descartar, como sugere o argumento da dupla distorção, o uso de meios de distribuição não fiscais.

${ }^{16} \mathrm{Na}$ verdade, não há apenas uma razão de justiça para preterir o imposto de renda por outros meios de distribuição (presumindo que esses meios sejam menos propensos à fuga). A fuga à jurisdição é uma distorção, porque, para realizá-la, os agentes consomem recursos que poderiam ser empregados de maneira socialmente mais útil. Dependendo da diferença entre o imposto de renda e outras regras no que se refere a essa distorção, é possível que o primeiro tenha de ser preterido inclusive com base em considerações de eficiência.
}

Revista do Direito UNISC, ISSN: 1982-9957

Santa Cruz do Sul №. 48 | p. 145-166 | JAN-ABR 2016

https://online.unisc.br/seer/index.php/direito/index 
fazer variar a indenização a pagar de acordo com a renda do causador do dano e da vítima se torna mais atraente depois de abandonada a presunção de que regras tributárias distributivas são inescapáveis ou tão difíceis de escapar quanto quaisquer outras.

Ao tratar de como a pré-distribuição requerida por uma democracia de cidadãos proprietários poderia ser assegurada mediante transferências, Williamson (2012) não deixa de notar a dificuldade para que essas transferências sejam custeadas mediante a tributação (2012, p. 227):

\begin{abstract}
Uma dificuldade econômica é que contribuintes ricos procurarão e encontrarão meios de transferir recursos financeiros para 0 estrangeiro a fim de fugir à tributação, seguindo o exemplo corrente de super-ricos e inúmeras corporações multinacionais. Preocupações com a riqueza que sai do país e com a competitividade global tiveram um papel crucial para persuadir países europeus como a Espanha e a Suécia a abrandar ou abandonar esquemas de tributação em anos recentes. Na ausência de uma verdadeira autoridade fiscal global, essa não é uma dificuldade que possa ser evitada, muito embora seja mais severamente sentida em economias pequenas, nas quais os custos de saída para os cidadãos ricos são relativamente baixos. A propriedade física e inamovível (por exemplo, imobiliária) constitui uma porção bastante larga do patrimônio do americano médio, mas uma porção relativamente pequena dos recursos dos super-ricos. Dinheiro em aplicações pode ser transferido instantaneamente ao redor do mundo, e se uma "onda" de redistribuição em larga escala se anunciar, um êxodo de capital certamente virá em sequência. ${ }^{17}$
\end{abstract}

Sintomaticamente, todas as soluções aventadas por Williamson (2012, p. 228) a fim de contornar a dificuldade descrita nessa passagem são fiscais: tributação dos fluxos de capital, tributação de bens inamovíveis (em particular, a terra), redução das alíquotas de imposto a patamares modestos o suficiente para não tornar a fuga atrativa e tributação das heranças. Tendo em vista o cenário a que Williamson se refere, no entanto, a dispersão da riqueza por

\footnotetext{
${ }^{17}$ No original: "One economic difficulty is that wealthy households will seek and find ways to move their financial assets abroad so as to evade taxation, following the current example of many of the super-rich as well as many multinational corporations. Concerns about wealth leaving the country and global competitiveness have played a key role in persuading EU countries such as Spain and Sweden to reduce or abandon wealth taxation schemes in recent years. In the absence of a truly global taxing authority, this is not a difficulty that can be avoided, though it will be most severe for relatively small economies where wealthy households have relatively low exit costs. Physical, non-movable property (i.e., housing) represents a very large share of wealth holdings for the average American, but a relatively small proportion of holdings for most super-rich households. Cash assets in saving accounts can be transferred around the world instantly, and if a large scale redistributive "moment" were known to be forthcoming in a single country, an exodus of such capital would be certain to follow."
}

Revista do Direito UNISC, ISSN: 1982-9957

Santa Cruz do Sul №. 48 | p. 145-166 | JAN-ABR 2016

https://online.unisc.br/seer/index.php/direito/index 
meios não fiscais, como as regras de direito privado sobre a propriedade, não deveria ser, sem mais, descartada. ${ }^{18}$

Outra lição a tirar das críticas ao argumento da dupla distorção é que pode valer a pena pensar em soluções institucionais pelas quais, ao invés apenas de transferências, a pré-distribuição seja lograda por um redesenho do sistema de direitos de propriedade no qual a eficiência seja, em alguma medida, sacrificada em prol dos objetivos de evitar a concentração da riqueza e assegurar que as decisões de mercado sejam tomadas em pé de relativa igualdade. ${ }^{19} \mathrm{Um}$ desafio para os interessados no ideal rawlsiano da democracia de cidadãos proprietários é, portanto, conceber e avaliar o potencial de propostas que, alternativamente à de Williamson (2012), procurem atender ao ideal pré-distributivo com regras de propriedade que contribuam para a igualdade dos agentes e reduzam, consequentemente, a necessidade das transferências. Será possível conceber um sistema de direitos de propriedade que apresente essas características sem sacrificar a eficiência em uma medida inaceitável? E será mesmo a reforma de tal sistema o caminho politicamente mais factível para uma democracia de cidadãos proprietários? São perguntas para a investigação futura.

\section{Referências}

AVRAHAM, Ronen; FORTUS; David; LOGUE, Kyle (2004). Revisiting the roles of legal rules and tax rules in income distribution: A response to Kaplow and Shavell. lowa Law Review, 89: 1.125-1.158.

COLANDER, David (2014). Piketty's policy proposals: How to effectively redistribute income. Real-World Economics Review, 69: 161-166.

DAGAN, Tsilly (2014). Pay as you wish: The global market for tax \& legal rules. Disponível em: http://ssrn.com/abstract=2506051. Acesso em: 25 fev. 2015.

\footnotetext{
${ }^{18}$ A preocupação com a inocuidade da tributação local como meio distributivo também está à base da proposta de Piketty (2013, cap. 15) de um imposto global sobre o capital.

${ }^{19}$ Repare como os argumentos de Fennell e McAdams (2015) também levantam suspeitas sobre o potencial distributivo de medidas não fiscais que pareçam impor perdas ou se contrapor aos resultados do mercado (ao invés de simplesmente definir as "regras do jogo"). Tendo isso em vista, as dificuldades políticas a que os autores citados se referem podem afligir quaisquer políticas de transferências, inclusive as que, ao invés do imposto de renda, valhamse de relações de direito privado, como, por exemplo, a relação entre a vítima e o causador do dano.
} 
DE GEEST, Gerrit (2014). Removing rents: Why the legal system is superior to the income tax at reducing income inequality. Washington University in St. Louis Legal Studies Research Paper n. 13-10-02. Disponível em: http://ssrn.com/abstract=2337720 ou http://dx.doi.org/10.2139/ssrn.2337720, Acesso em: 25 fev. 2015.

GALLE, Brian (2010). Is local consumer protection law a better redistributive mechanism than the tax system? New York University Annual Survey of American Law, 65: 525-544.

HSIEH, Nien-hê (2012). Work, ownership, and productive enfranchisement. In: O'NEILL, Martin; WILLIAMSON, Thad. (orgs.). Property-owning democracy: Rawls and beyond. Malden: Blackwell, cap. 7.

JACKSON, Ben (2012). Property-owning democracy: A short history. In: O'NEILL, Martin; WILLIAMSON, Thad. (orgs.). Property-owning democracy: Rawls and beyond. Malden: Blackwell, cap. 2.

JOLLS, Christine (1998). Behavioral economic analysis of redistributive legal rules. Vanderbilt Law Review, 51: 1.653-1.677.

KLAPOW, Louis; SHAVELL, Steven (1994). Why the legal system is less efficient than the income tax in redistributing income. Journal of Legal Studies, 23: 667-681.

KAPLOW, Louis; SHAVELL, Steven (2000). Should legal rules favor the poor? Clarifying the role of legal rules and the income tax in redistributing income. Journal of Legal Studies, 29: 821-835.

KEREN-PAZ, Tsachi (2007). Torts, egalitarianism and distributive justice. Hampshire: Ashgate.

KERR, Gavin (2015). "Pré-distribution", property-owning democracy and land value taxation. Politics, Philosophy \& Economics, publicado on line antecipadamente. DOI: 10.1177/1470594X15573458.

LEWINSOHN-ZAMIR, Daphna (2006). In defense of redistribution through private law. Minnesota Law Review, 91: 326-397.

LOGUE, Kyle; AVRAHAM, Ronen (2003). Redistributing optimally: Of tax rules, legal rules, and insurance. Tax Law Review, 56: 157-258.

McADAMS, Richard H.; FENNELL, Lee Anne (2015). The distributive deficit in law and economics. Coase-Sandor Working Paper Series in Law and 
Economics, $\quad$ n. $713 . \quad$ Disponível em: http://papers.ssrn.com/sol3/papers.cfm?abstract id=2544519. Acesso em: 21 mai. 2015.

MEADE, James E. (2012)[1964]. Efficiency, equality and the ownership of property. Abingdon: Routledge.

O'NEILL, Martin (2012). Free (and fair) markets without capitalism: Political values, principles of justice, and property-owning democracy. In: O'NEILL, Martin; WILLIAMSON, Thad. (orgs.). Property-owning democracy: Rawls and beyond. Malden: Blackwell, cap. 4.

O'NEILL, Martin; WILLIAMSON, Thad (2012). The promise of pré-distribution. Policy Network, 28 set. 2012. Disponível em: http://www.policynetwork.net/pno detail.aspx?|ID=4262\&title=The-Promise-of-Pre-distribution.

Acesso em: 20 mar. 2015.

PIKETTY, Thomas (2013). Le capital au XXI siècle. Paris: Seuil.

RAWLS, John (1999)[1971]. A theory of justice. 2 ed. Cambridge (EUA): Belknap Press, 1999.

RAWLS, John (2001). Justice as fairness: A restatement. Cambridge: Belknap Press.

SANCHIRICO, Chris William (2000). Taxes versus legal rules as instruments for equity: A more equitable view. Journal of Legal Studies, 29: 797-820.

SANCHIRICO, Chris William (2001). Deconstructing the new efficiency rationale. Cornell Law Review, 86: 1.003-1.089.

WILLIAMSON, Thad (2012). Realizing property-owning democracy: A 20-year strategy to create an egalitarian distribution of assets in the United States. In: O'NEILL, Martin; WILLIAMSON, Thad. (orgs.). Property-owning democracy: Rawls and beyond. Malden: Blackwell, cap. 11. 